\title{
Core Competencies for the Practice of Tertiary Learning Advising in New Zealand
}

\section{Mona Malik}

Manukau Institute of Technology Ltd, Auckland, New Zealand

mona.malik@manukau.ac.nz

\begin{abstract}
Tertiary learning advising is an established profession within the tertiary education system in New Zealand, with a representative professional body of its own - the Association of Tertiary Learning Advisors of Aotearoa New Zealand (ATLAANZ) - and a self-aware, well-informed, and evolving professional practice. However, the role is seldom duly acknowledged within the institutions, and tertiary learning advisors (TLAs) often struggle with issues of lack of a definitive professional identity and clear pathways of recognition and progression within the role. This paper argues that to address these issues, it will be useful to construct a core competencies model for tertiary learning advising that provides a clear definition of the abilities and aptitudes required in the role, and that corresponds with the principles, values, knowledge, skills, and responsibilities identified as essential for professional practice of tertiary learning advising. The paper considers two existing competency models/frameworks, namely NACADA Academic Advising Core Competencies Model and The UKAT Professional Framework for Advising and Tutoring, from the related fields of academic advising and personal tutoring, and proposes a Core Competencies Model for Tertiary Learning Advising in New Zealand that can potentially be an integral part of a formal recognition or accreditation scheme for TLAs.

Keywords: core competencies, core competencies model, tertiary learning advising, professional practice, recognition/accreditation scheme
\end{abstract}

Tertiary learning advisors (TLAs) are professional educators who work with students to support them in developing their academic literacy and understanding of the expectations of tertiary study, to facilitate the achievement of their academic goals (Griffith University, 
n.d.). Academic literacy denotes the ability to use language that meets the demands of tertiary education; that is, to gather information from various sources, process and interpret that information by analysing it, and produce new information. This new information is generally required to be communicated in writing, expressing one's understanding in a voice which, though formed in collaboration with other's views and opinions, is distinctly one's own (Weideman, 2018). In New Zealand tertiary education, TLAs are instrumental in providing learning support to encourage development of students' academic literacy and essential study skills. However, the role is seldom duly acknowledged within the institutions, and TLAs often struggle with the lack of a definitive professional identity and clear pathways of recognition and progression. In this paper, I argue that, to address these issues, it will be useful to construct a core competencies model for tertiary learning advising that provides a clear definition of the abilities and aptitudes required in the role, and that corresponds with the principles, values, knowledge, skills, and responsibilities identified as essential for professional practice of tertiary learning advising.

My paper proceeds in three sections. First, it examines the contemporary tertiary education context in New Zealand and the need therein for learning advising to provide relevant academic support. It then it provides a brief historical background of tertiary learning advising as a profession in New Zealand, followed by a discussion of the significant issues currently being faced by TLAs. Finally, drawing upon two existing models/frameworks, namely the National Academic Advising Association (NACADA) Academic Advising Core Competencies Model and The United Kingdom Advising and Tutoring Association (UKAT) Professional Framework for Advising and Tutoring, from the related fields of academic advising and personal tutoring, respectively, it proposes a Core Competencies Model for Tertiary Learning Advising in New Zealand.

\section{Contemporary New Zealand Tertiary Education Context}

The internationally emerging tertiary study environment over the past few decades has been greatly impacted by the neoliberal trends of public disinvestment, privatisation, and increased focus on value of higher education for individual, social, and national prosperity (Shear \& Hyatt, 2017). Furthermore, the adoption of new business models in higher education in recent times have led to an increasing influence of technological innovation to enhance efficiency and modify pedagogical approaches as required by demands of economic progress and globalisation (Anderson et al., 2012). 
The evolving tertiary environment in New Zealand is marked by similar trends and patterns. As stated by Sedgwick and Grey (2018), the focus of New Zealand tertiary education since the 1980s has been re-directed from transformative learning and critical inquiry towards the goals determined by the new public management approach of meeting market targets and effecting economic growth. This market model of education is characterised by competition among tertiary institutions for students and funding, hardening of soft budgetary constraints, performance management and monitoring, audit and checking systems, development of strong executive and managerial roles, reduction in faculty representation in management, and declining local government influence on the administration of universities, polytechnics, and wānanga (Ferlie et al., 2008). Consequently, there has been a significant increase in constraints on professional autonomy and academic freedom of tertiary educators (Sedgwick \& Grey, 2018).

In the years 2013 and 2016, surveys were conducted on State of Tertiary Education Sector in New Zealand to assess staff opinion about the levels of academic freedom they believed they had. Participants in these surveys were academic and general (allied, professional, and business support) staff from various public tertiary education institutions, that is, universities, Institutes of technology and polytechnics (ITPs) and wānanga across New Zealand. Two of the aspects relating to academic freedom in these surveys are particularly relevant for TLAs in contemporary tertiary education settings: increasing pressure to pass a higher percentage of students and admit students into programmes without prerequisites or adequate prior experience/skills.

For the first aspect, it was found that there exists a clear directive for wānanga and polytechnic staff to pass more students and to, a lesser degree, for university staff to do the same. Compared to 59.4\% of 1653 respondents in 2013 survey (Bentley at al., 2014), 63.1\% of the 635 respondents who answered the relevant question in the 2016 survey saw this pressure as getting worse (Sedgwick \& Grey, 2018). With regards to admission of less qualified or ill-prepared students — one of the measures added in 2016 to achieve a more nuanced view of academic freedom - the situation was particularly concerning, with $65 \%$ of university staff and $71 \%$ of polytechnic staff believing that the pressure to admit such students is growing (Sedgwick \& Grey, 2018). Given these pressures, relevant and professional academic support for all students, including those who may be inadequately prepared for tertiary study, is essential for meeting the educational outcomes of lifelong learning as well as market outcomes for development of human capital. 
However, contrary to what may be required in this situation, the provision of study skills and learning support was found to have fallen over the three years following the 2016 survey (Sedgewick \& Proctor-Thomson, 2019). As reported in the latest State of Public Tertiary Education Sector Survey, 2018, 25.9\% of academic and general staff described the academic support available at their institutions as inadequate. One of the general staff respondents at a university noted, "We used to offer excellent learning support in the library, but we have lost many opportunities for teaching and learning due to a cost-cutting selfservice approach" (Sedgewick \& Proctor-Thomson, 2019, p. 25).

Furthermore, just over half the academics in this survey (57.8\%) reported having inadequate time to offer necessary study and learning support to students due to the reduction of academic student support services and increasing workloads. One of the 2018 university academic respondents remarked, "I do what I can, but with some workdays 12-16 hrs in length, I worry about compassion fatigue and burnout. I pride myself in being excellent in this area [supporting students], but in truth time constraints and other work...means that's not always true" (Sedgewick \& Proctor-Thomson, 2019, p. 26). A similar number of ITP academics - approximately $60 \%$ - reported having inadequate time for the student support aspects of their role (Sedgewick \& Proctor-Thomson, 2019). This situation, therefore, highlights the need to provide well-funded and well-resourced academic support services and to encourage best practice in tertiary learning advising in New Zealand institutions.

\section{Tertiary Learning Advising as A Profession in New Zealand}

From a historical perspective, tertiary learning advising may be regarded as a relatively new professional role in the conventional system of Western tertiary education, with first distinct reference to the need of addressing study skills deficit in first-in-family students being registered in the 1950s in Australia (Anderson \& Eaten, as cited in Harper, 2018). In New Zealand, as stated by Cameron and Catt (2014), learning advisors have been employed in tertiary institutions since the mid-1980s, and their professional organisation, the Association of Tertiary Learning Advisors of Aotearoa New Zealand (ATLAANZ) was formally constituted in 2000 (Cameron \& Catt, 2014). The Association aims to facilitate communication, networking, and sharing of ideas to promote good learning advisory practice in tertiary institutions; provides professional development opportunities for its members; and encourages regular publication of research and other useful resources for TLAs (ATLAANZ, n.d.). In 2012, ATLAANZ officially adopted a professional practice document describing the principles and values, knowledge and skills, and roles and responsibilities of TLAs in New 
Zealand. By consensus, the document is regarded as a dynamic manuscript that needs to be endorsed by members every two years (Cameron, 2018a). In these ways, TLAs in New Zealand constantly strive to maintain a self-aware, well-informed, and evolving professional practice.

\section{Issues of Professional Identity and Role Recognition of TLAs in New Zealand}

Despite TLAs' sincere endeavours, coupled with the clear need for robust learning advisory practice, the TLA role is generally under-appreciated, even invisible, within New Zealand tertiary education institutions. This is attributed to two inter-related issues currently faced in the profession, namely, professional identity and role recognition (Cameron, 2018c).

The language a profession uses to describe itself is essential to its identity (Cameron, $2018 \mathrm{~b}$ ). It has been argued that the work of TLAs is "academic, scholarly, professional and integral to teaching and learning in tertiary education today" (Crozier, 2007, as cited in Cameron, 2018b, p. 40). This is also reflected in the roles, responsibilities, knowledge, skills, and practice of TLAs delineated in the Association's professional practice document (ATLAANZ, 2012). However, this self-perception of identity of TLAs is in dissonance with the identity their institutions assume for them, obvious in the variety of employment agreements on which TLAs are employed, and organisational policy barriers related to salary scales and criteria for advancement (Cameron, 2018b).

Learning advisors are employed on a range of agreements: academic, general (also called allied or professional), and 'other' (usually individual agreements). Within these broad categories, some learning advisors are paid on the same scale as non-TLA colleagues in their institution (that is, faculty teaching staff for those on academic contracts; or library/administrative staff for those on general agreements), while others are on a scale specifically for TLAs (Cameron, 2018b). According to the findings of a survey conducted in 2014 to explore the personal and professional profile of learning advisors in universities, institutes of technology and polytechnics (ITPs), wānanga, and private training organisations, $48 \%$ of respondents on academic contracts were paid $\$ 80,000$ FTE and above, compared to only $20 \%$ of those on general contracts. Overall, there is an increasing trend to employ learning advisors on general contracts, exerting a downward pressure on their salaries in the future (Cameron, 2018b).

Further, the 2014 survey revealed that being on an academic agreement does not necessarily ensure recognition of TLAs' contribution to learning and teaching, as the 
progression pathways in academic collective agreements are often unrealistic for the TLA role. These promotion criteria are designed to suit the course-related responsibilities of their faculty teaching colleagues. Thus, the survey findings point to organisational culture barriers to advancement, caused by a general lack of understanding amongst management or promotion committees about what the learning advisor role requires (Cameron, 2018b). The sense of bleak career prospects this generates within the profession was expressively and clearly summed up in one of the responses in this survey: "Redundancy, retirement, or death are the only events likely to change the status of a learning advisor here" (Respondent 79, as cited in Cameron, 2018b, p. 36).

As rightly explained by Cameron (2018b), this situation in relation to employment agreements and accompanying career barriers is being faced by TLAs, because learning advising is a new profession finding its way within the well-established conventions, structures, and policies of an old institution. Accordingly, the role is often determined by management processes consisting of improvised and ad hoc measures. This results in a mismatch between the identity constructed by TLAs themselves over the past three or four decades, and the one perceived by established organisational management. To address this dissonance in perceptions of professional identity, it will be important to ensure a formal and categorical recognition of competencies, knowledge, and skills demonstrated in tertiary learning advisory practice (Cameron, 2018b).

\section{Issues of Representativeness and Sustainability in Current New Zealand TLA Profile}

Another challenge identified for the profession in its current profile is the underrepresentation of Māori and, to a lesser degree, Pacific populations (Cameron, 2018a). For example, in 2014, Pacific students comprised $9 \%$ of ITP and $7 \%$ of university enrolments, and Māori students 23\% and 11\% respectively (New Zealand Ministry of Education, 2016, as cited in Cameron, 2018a). However, between 2014 and 2017, it was reported that approximately $8 \%$ of ATLAANZ members identified as Pacific but only $7 \%$ identified as Māori (Simkin, 2017, cited in Cameron, 2018a). Therefore, more Māori professionals in particular need to be encouraged into the TLA role.

Also, the profession's current membership is heavily imbalanced in gender and age: almost $60 \%$ of respondents to the 2014-survey exploring TLAs' profile and self-perception of their roles were over 50 years of age and 82\% were women (Cameron, 2018a). This underrepresentation of males may be attributed to the arguably low-status of the TLA role in 
tertiary education, a fact echoed in research on other low-stakes roles in academia (Doyle et al., 2005, as cited in Cameron, 2018a). The skewed age profile poses a more serious challenge; although it resonates with the overall greying character of tertiary teaching profession, it presents a greater concern for the sustainability and succession planning in tertiary learning advising. Therefore, there is an explicit need to actively employ, encourage, develop, and retain younger staff (Cameron, 2018a).

\section{Need for a Professional Accreditation Scheme for TLAs}

It has been suggested that the issues discussed above could be addressed through the adoption of a formal recognition or accreditation scheme that defines the practice clearly; informs institutions about TLAs' competencies, values, skills and attributes; and categorically articulates the role requirements for recruitment purposes (Cameron, 2018c). As argued by Cameron (2018a), several benefits may accrue from the development of such an accreditation scheme, such as making the role visible as a promising potential career to prospective learning advisors, and providing pathways for ongoing mentoring and training for inexperienced TLAs. This would be particularly relevant to address the under-representation of younger staff in the profession. Finally, "a professional recognition, or accreditation scheme would provide meaningful peer-validation of identity" (Cameron, 2018c, p. 62). This implies that, for senior TLAs who persevere in the role, accreditation might provide the necessary formal acknowledgement from colleagues and peers, thereby, encouraging better retention.

\section{Core Competencies Models for Advising}

My paper proposes that, as part of any accreditation or formal recognition scheme suggested for TLAs in New Zealand, a core competencies model for their professional practice also be formulated. The competencies in the model would correspond with the principles and values, knowledge and skills, and roles and responsibilities outlined in the ATLAANZ professional practice document (ATLAANZ, 2012). It would also align with similar competencies models developed for advising professionals (also known as academic advisors and personal tutors) in different national contexts.

It is pertinent to consider international competencies models for academic advisors and personal tutors because these roles include similar responsibilities to TLAs in providing skilled and professional advice/support to students in tertiary education. The models presented here, NACADA from the United States and UKAT from Great Britain, 
acknowledge the need to place advising in the centre of student success initiatives in higher education and to define the understanding and practice of advising clearly within the regional/national contexts (McGill et al., 2020).

\section{NACADA Academic Advising Core Competencies Model}

The Global Community for Academic Advising in the United States (NACADA) regards academic advising as fundamentally grounded in the teaching and learning mission of higher education, and defines it as:

a series of intentional interactions with curriculum, a pedagogy, and a set of student learning outcomes. Academic advising synthesizes and contextualizes students' educational experiences within the frameworks of their aspirations, abilities, and lives to extend learning beyond campus boundaries and timeframes. (NACADA, 2006, Summary section, para. 9)

NACADA's professional development committee developed its Core Competencies Model of Academic Advising (NACADA, 2017) to distinguish the range of conceptual understanding, informational knowledge, and relational skills associated with academic advising; to guide advisors' professional development; and to encourage advisor contributions to student advancement and success. It aims to foster the development of training and assessment processes in the work of primary-role advisors, faculty advisors, advising managers and mentors, learning professionals, researchers and trainers (NACADA, 2017).

As shown in Figure 1, the model delineates three major competency areasconceptual, informational, and relational - that promote excellent advising practice. Regardless of the differences between individual institutional missions and objectives, all the three components are crucial to be understood and successfully integrated and applied by all advisors in their advising interactions to achieve excellence (NACADA, 2017). 


\section{Figure 1}

NACADA Core Competencies Model for Academic Advisors

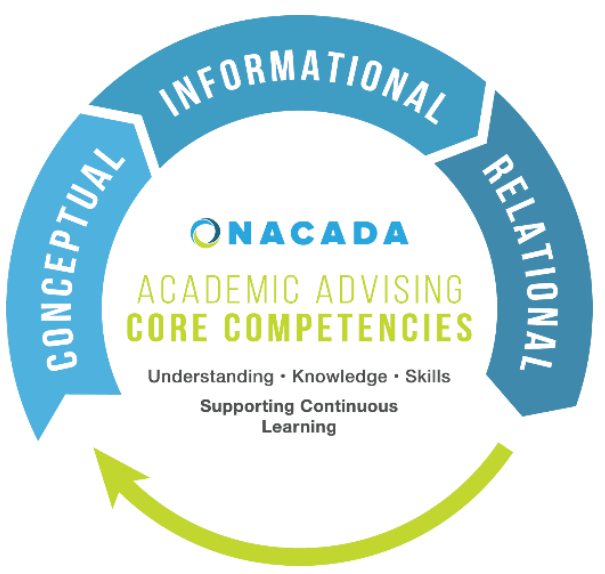

Note: Reprinted with permission from NACADA Academic Advising Core Competencies Model, Copyright 2017 by NACADA: The Global Community for Academic Advising.

https://www.nacada.ksu.edu/Resources/Pillars/CoreCompetencies.aspx

Within the conceptual component, core competencies include an understanding of:

1. The history and role of academic advising in higher education

2. NACADA's Core Values of Academic Advising

3. Theory relevant to academic advising

4. Academic advising approaches and strategies

5. Expected outcomes of academic advising

6. How equitable and inclusive environments are created and maintained (NACADA, 2017)

For the informational component, advisors must demonstrate knowledge of:

1. Institution specific history, mission, vision, values, and culture

2. Curriculum, degree programs, and other academic requirements and options

3. Institution specific policies, procedures, rules, and regulations

4. Legal guidelines of advising practice, including privacy regulations and confidentiality

5. The characteristics, needs, and experience of major and emerging student populations

6. Campus and community resources that support student success

7. Information technology applicable to relevant advising roles (NACADA, 2017) 
For the relational component, core competencies include advisors' ability to:

1. Articulate a personal philosophy of academic advising

2. Create rapport and build academic advising relationships

3. Communicate in an inclusive and respectful manner

4. Plan and conduct successful advising interactions

5. Promote student understanding of the logic and purpose of the curriculum

6. Facilitate problem solving, decision-making, meaning-making, planning, and goal setting

7. Engage in on-going assessment and development of advising practice (NACADA, 2017)

NACADA Academic Advising Core Competencies Model serves to provide academic advisors with a basis to identify the breadth and depth of their role in facilitating student success. It is a fundamental document that gives purpose and direction to academic advising (Council for the Advancement of Standards in Higher Education [CAS], 2019). NACADA evolved from the first national conference of academic advisors held at the University of Vermont in 1977. It was officially chartered in 1979 (Thurmond \& Miller, 2006), and today the organisation has grown to include nearly 14000 members from 35 countries (Sannes, 2018). One of the reasons for its growth may be that its core competencies contribute to enabling a notion of academic advising that is inclusive, adaptable, and responsive to the diversity in institutions, organisational structures, advisors, and student populations.

Academic advising in the higher education institutions in the United States involves helping students explore their academic interests, locate resources of relevant information, and develop plans for study corresponding to their educational goals. The intensive support is based on advisors' regular contact with advisees and often involves referrals to other campus services for academic skills development, financial aid, personal development, and career counselling (Academic Advising Center, n.d.). Some of the aspects of North American academic advising - for example, regular professional contact with students in advising sessions, being mindful of students' educational goals to provide relevant support and/or make referrals to other campus services - resonate with similar facets of the TLA role in New Zealand. Hence, some of core competencies defined in the NACADA Academic Advising Core Competencies Model are also relevant for the practice of tertiary learning advising in New Zealand. 


\section{The UKAT Professional Framework for Advising and Tutoring}

Based on the NACADA model, the United Kingdom Professional Framework for Advising and Tutoring (UKAT, 2019) defines the core competencies for personal tutors and academic advisors to successfully support students' academic success. It aims to encourage best practice of advising/personal tutoring and thereby raise its recognition and perceived value in higher education today. Historically, personal tutoring in the UK involved supporting students with their academic skills and course work, but the role has since been extended to include pastoral support and assistance for personal development, in addition to academic support (McGill et al., 2020).

Personal tutoring, as understood in the UK higher education, is akin to advising in the US context (Sannes, 2018), and its association with NACADA may be traced back to 2006 when Charlie Nutt, then NACADA Executive Director, was invited to present at a regional tutoring conference in the UK. He realised that “...this group, on another continent, had the same concerns in supporting student success as North American advisors" (Sannes, 2018, para.5). Subsequently, the UKAT association for professional advisors and researchers interested in advising and personal tutoring in higher education was founded in 2015 (UKAT, n.d.-a).

Three distinct types of personal tutoring operate in the UK higher education institutions: pastoral, wherein academic staff provide personal and academic support; professional, wherein students are referred to centralised professional services; and integrated, wherein personal tutoring is part of the curriculum and delivered by academics (Earwaker, as cited in Raby, 2020). Currently most institutions implement a hybrid of these types (McFarlane, 2016), all of which aim to enable students make connections between different elements of learning experience and realise their higher educational goals (Woods, 2020). Therefore, the core competencies delineated in the UKAT Professional Framework for Advising and Tutoring are also potentially applicable to tertiary learning advising as practised in New Zealand. 


\section{Figure 2}

The UKAT Professional Framework for Advising and Tutoring

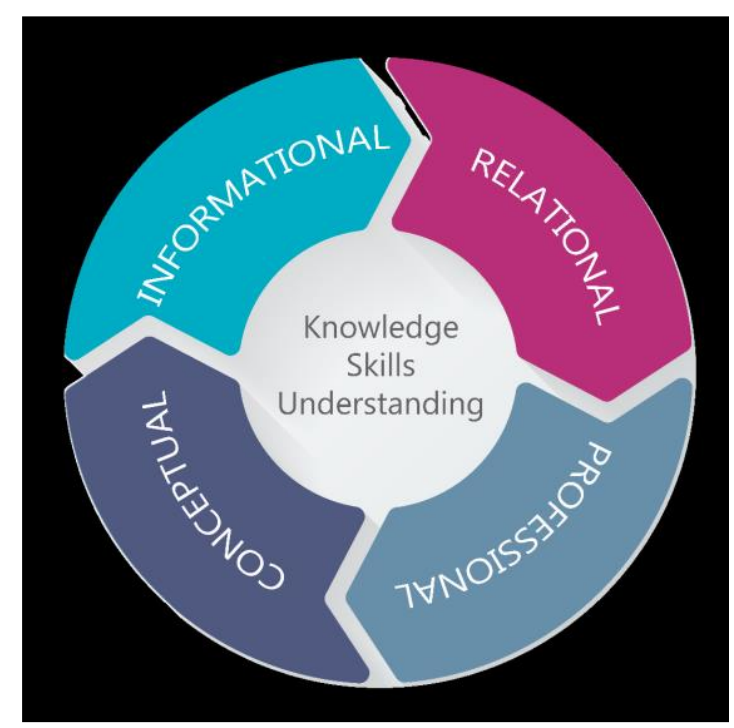

Note: From Professional framework for advising and tutoring, by United Kingdom Advising and Tutoring, 2019, https://www.ukat.ac.uk/framework. Copyright 2019 by UK Advising and Tutoring. Reprinted with permission.

As shown in Figure 2 above, there are four competency areas in the framework: three - conceptual, informational, and relational - have been adapted from the NACADA Academic Advising Core Competencies Model and have a comparable focus, namely advisors' and tutors' understanding of theories and approaches of advising, their knowledge, and their skills, respectively (McGill et al., 2020). The fourth component_professional —is specific to the UKAT Framework and is centred on advisors and tutors' commitment to the students they advise, their institutions, their professional practice, and the wider educational community (UKAT, 2019). The professional component has clear similarities with the New Zealand learning advisor role, and describes the ability of advisors and tutors to:

1. Create and support environments that consider the needs and perspectives of students, and respect individual learners

2. Appreciate students' views and cultures, maintain a student-centred approach and mindset, and treat students with sensitivity and fairness

3. Commit to students, colleagues, and their institutions through engagement in continuing professional development, scholarly enquiry, and the evaluation of professional practice 
4. Understand the implications of quality assurance and quality enhancement, and engage in on-going evaluation and development of advising and tutoring practice (UKAT, 2019).

In several tertiary institutions in the UK, the UKAT Professional Framework for Advising and Tutoring, provides the benchmark against which the evidence of work done by tutors and advisors is referenced and assessed for its value and effectiveness in supporting student success. It forms the basis for the UKAT Professional Recognition scheme that aims to acknowledge advisors'/tutors' contributions, and encourage reflective practice informed by scholarship in the field for continuous enhancement of quality (UKAT, n.d.-b). The scheme, involving submission of an e-portfolio of retrospective evidence of practice and providing clear pathways for scaffolded enhancement, allows tutors and advisors to gain recognition at one of three levels: Recognized Practitioner in Advising-RPA, Recognised Senior Advisor-RSA and Recognised Leader in Advising-RLA (UKAT, n.d.-b). The UKAT Professional Recognition, piloted in 13 institutions since June 2020, has progressively gained significant success and acceptance in higher education in the UK (Draper \& Barton, n.d.).

\section{Proposed Core Competencies Model}

\section{for TLAs' Professional Practice in New Zealand}

I argue that, in New Zealand, tertiary learning advising as a profession could also benefit from developing a core competencies model that is suitable within the national context, by using some standards/competencies articulated in the NACADA model of Academic Advising and the UKAT Professional Framework for Advising and Tutoring as valuable suggestions and reworking them according to needs and priorities of tertiary education in New Zealand. Such a model would help guide TLAs' professional practice by identifying the essential expertise, skills, and aptitudes needed to provide effective academic support for tertiary students. In addition, this model may form part of a professional accreditation or recognition scheme for TLAs as suggested by Cameron (2018c) to inform institutions about TLA competencies and facilitate defining the role requirements clearly for recruitment purposes.

The proposed Core Competencies Model for Tertiary Learning Advising presented in Figure 3 below is based on my nearly seven years' experience as a tertiary learning advisor in New Zealand, and consists of four categories, self-, profession-, institution-, and studentrelated competencies, depicted as layers in an upright pyramid. The progressively tapering 
magnitude of component layers reflects the number of competencies in each category, with the largest — student-related competencies — forming the base of the pyramid. This is justified since the predominant part of TLAs' work is student related. The pyramid itself is positioned within the regional/national context, represented by an open-ended encircling arrow to reflect its dynamic nature, responsive to influences from beyond the immediate environment in an increasingly connected contemporary world.

\section{Figure 3}

Core Competencies Model for Tertiary Learning Advising in New Zealand

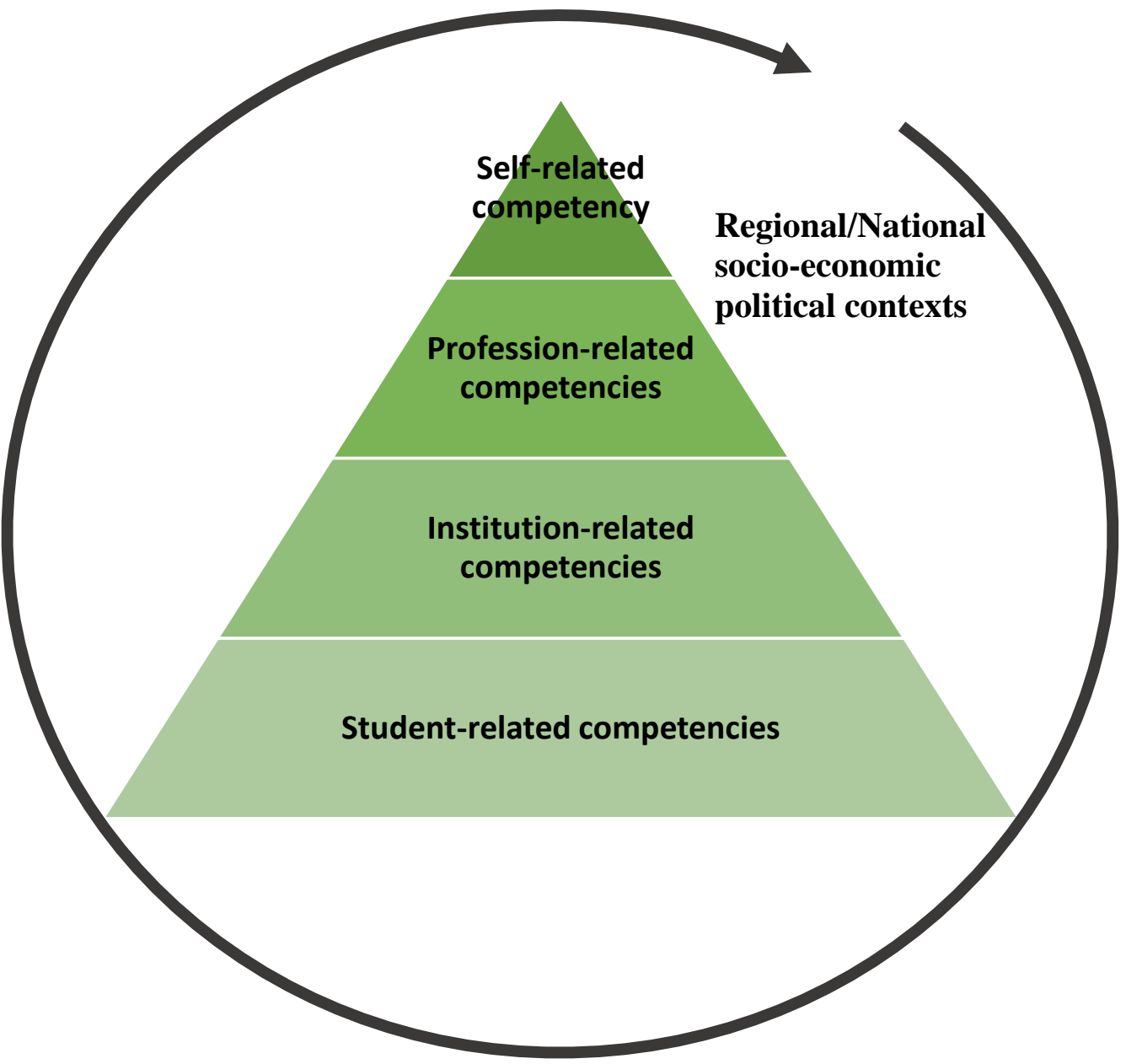

The proposed competencies, with their respective focus, are listed in Table 1 below: 


\section{Table 1}

\section{Competencies and Their Focus in the Role of TLAs}

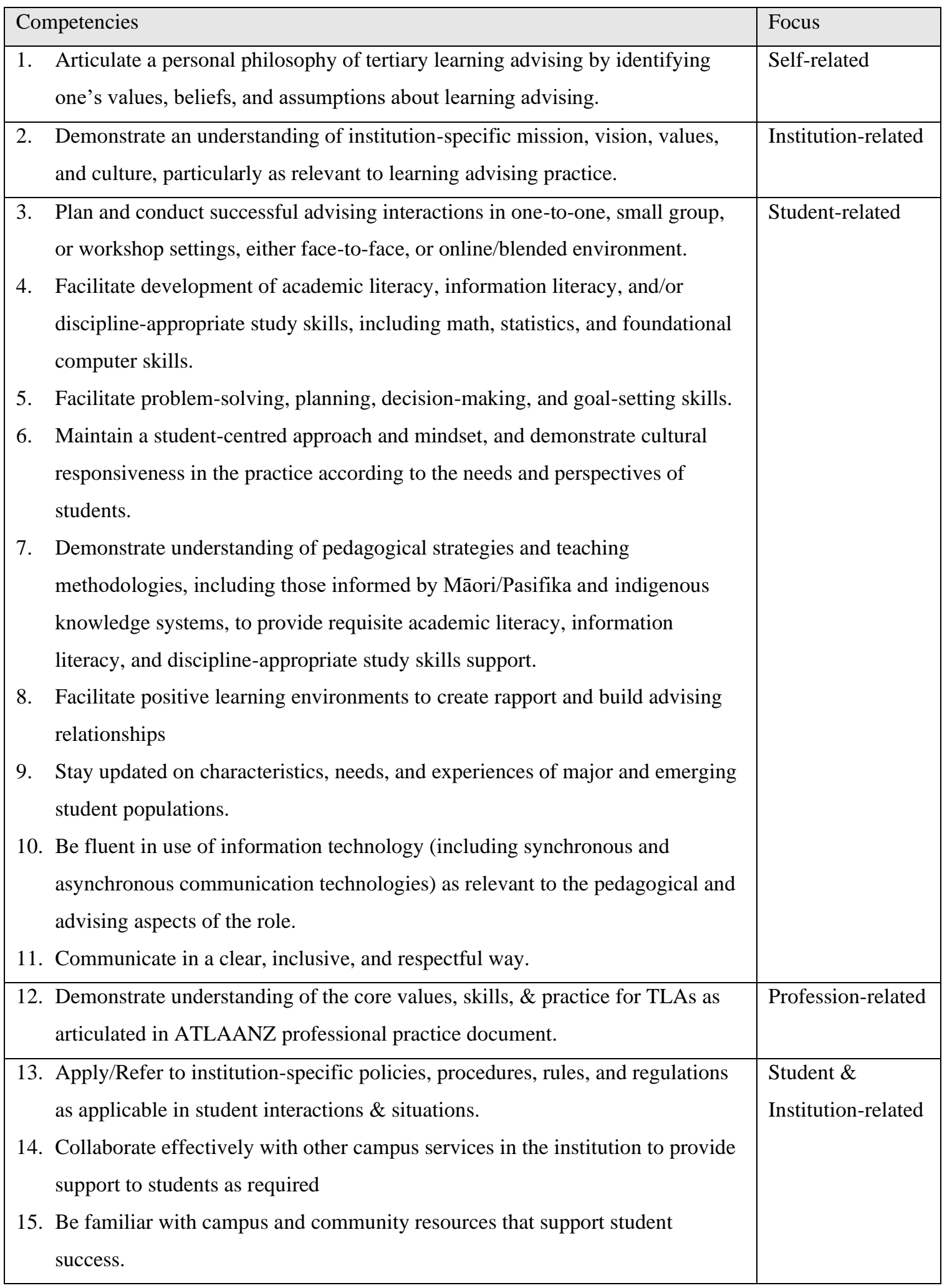




\begin{tabular}{|c|c|}
\hline Competencies & Focus \\
\hline $\begin{array}{l}\text { 16. Develop awareness and understanding of advising approaches and strategies } \\
\text { (from the related fields of academic advising/personal tutoring) as relevant to } \\
\text { tertiary learning advising. }\end{array}$ & $\begin{array}{l}\text { Student \& } \\
\text { Profession-related }\end{array}$ \\
\hline $\begin{array}{l}\text { 17. Actively collect evidence of outcomes of advising and evaluate impact made } \\
\text { through the support/advice offered and participate in institutional process of } \\
\text { quality assurance and advancement. } \\
\text { 18. Follow legal and professional guidelines of learning advising, including } \\
\text { privacy regulations and confidentiality. } \\
\text { 19. Engage in ongoing self-assessment, reflective practice, and professional } \\
\text { development to maintain and promote evidence-based practice of tertiary } \\
\text { learning advising } \\
\text { 20. Stay updated on the evolving regional/national context of tertiary education } \\
\text { and participate in the process knowledgeably to ensure continued professional } \\
\text { best practice. }\end{array}$ & $\begin{array}{l}\text { Student, } \\
\text { Institution \& } \\
\text { Profession-related }\end{array}$ \\
\hline
\end{tabular}

As evident from the list, there are four categories of competencies depending on their distinct focus, however, the categories intersect. Student-related competencies form the largest category in the list above, comprising 17 out of 20 competencies, with nine having an exclusive student focus (Competencies 3-11). This highlights the student-centred nature of best practice in tertiary learning advising. Institution-related competencies form the next group with eight competencies addressing institution-level requirements and aspirations, applicable to provision of academic support. The third category is profession-related competencies, with six describing abilities that TLAs need to demonstrate and/or develop to participate actively in maintaining and advancing tertiary learning advising as a robust, evolving profession. The sole self-related competency refers to the ability for self-aware practice and has a sharp focus on individual TLAs' own values, beliefs, and assumptions about their practice of learning advising and its purpose. The definitive character of these competencies would be eventually determined and continuously influenced by the regional/national contexts, in response to current socio-economic conditions and governmental/political ideologies and priorities.

The list of competencies constituting the model may provide a guiding reference for recruitment and/or training of new or relatively inexperienced learning advisors, as well as for ongoing professional development of experienced TLAs. The competencies with an exclusive student focus (Competencies 3-11) could be used by employers during the 
recruitment and selection procedure at their institution to guide their choice of suitable professional educators for the TLA role. Typically, relevant discipline-specific qualifications, along with professional teaching qualifications and experience, equip educators with these competencies. In the first three years of the TLA role, the self-related competency (Competency 1), the specific institution-related competency (Competency 2), the exclusively profession-related competency (Competency 12), and the set of competencies with both student and institutional focuses (Competencies 13-15) may be considered as high priority and encouraged through relevant training and professional development opportunities. Subsequently, the other competencies (Competencies 16-20) may be continuously developed and refined with growing experience by undertaking research and/or formal higher education endeavours. Furthermore, competencies may need to be re-visited and re-assessed throughout in a TLA's career as part of ongoing professional development and/or to address everchanging contextual elements.

\section{Conclusion}

The provision of quality academic literacy and study skills support is vital for improving student success and retention rates in contemporary tertiary education in New Zealand. With the adoption of market models in education, academic staff find themselves increasingly constrained in providing required academic literacy and study skills support to students due to increased workloads in general and higher pressure to pass students in polytechnics and wānanga in particular. TLAs, who are professional educators skilled in providing academic support, can offer an immensely relevant facility within contemporary tertiary education. However, the role is largely undervalued and often remains invisible in institutions, with no provision for formal recognition procedures or clear route of career progression. The profession, therefore, faces a significant risk of becoming unsustainable in the long-term, unable to recruit and retain young and/or highly skilled learning advisors. As suggested by Cameron (2018c), a professional accreditation or recognition scheme for TLAs can help in addressing some of these issues.

My paper has argued that having a core competencies model as an important component of such a scheme can help in identifying the required abilities, attributes, and expertise for the role, and in defining standards of best practice in tertiary learning advising. International models for academic advising and tutoring have been explored as they aim to define the practice of advising clearly within their respective national contexts for roles that have similar responsibilities to tertiary learning advising in New Zealand. By reworking 
standards articulated in the NACADA model of Academic Advising and the UKAT Professional Framework for Advising and Tutoring, I propose a Core Competencies Model for tertiary learning advising in New Zealand. Further discussion within the profession is required to agree on the need for such a model within a formal recognition scheme for TLAs in New Zealand. A generally accepted Core Competencies Model could serve as a foundation for ongoing professional practice of learning advising that would visibly contribute to positive student learning outcomes in contemporary New Zealand tertiary education. 


\section{References}

Academic Advising Center. (n.d.). What we do. Iowa. https://advisingcenter.uiowa.edu/what$\underline{\text { we-do }}$

Anderson, J., Boyles, J.A., \& Raine, L. (2012). The future of higher education. http://www.pewinternet.org/2012/07/27/the-future-of-higher-education/

Association of Tertiary Learning Advisors of Aotearoa/New Zealand. (n.d.). About us: What is ATLAANZ? ATLAANZ. https://www.atlaanz.org/about/

Association of Tertiary Leaning Advisors of Aotearoa/New Zealand. (2012). ATLAANZ professional practice document.

https://drive.google.com/file/d/1CnutqWANMvvvIMZT4mTUDyeQvaieVoQZ/view

Bentley, T., McLeod, L., \& Teo, S. (2014). The state of the tertiary education sector in New Zealand-2013. Tertiary Education Union, Te Hautū Kahurangi o Aotearoa. https://assets.website-

files.com/5c6dcbdefb133660ed1ad071/5cecb4ace2f3079c0d55acb1_State\%20of\%20t he\%20Tertiary\%20Education\%20Sector\%202013.pdf

Cameron, C. (2018a). Tertiary learning advisors in Aotearoa/New Zealand: Part one: Building a profile of our profession: Identity and opportunity [Special issue]. ATLAANZ Journal, 3, 1-24. https://doi.org/10.26473/ATLAANZ.2018.1/002

Cameron, C. (2018b). Tertiary learning advisors in Aotearoa/New Zealand: Part two: Acknowledging our contribution: Identity and opportunity [Special Issue]. ATLAANZ Journal, 3, 25-43. https://doi.org/10.26473/ATLAANZ.2018.1/003

Cameron, C. (2018c). Tertiary learning advisors in Aotearoa/New Zealand: Part three: Why do we stay? Rewards and challenges: Identity and opportunity [Special issue]. ATLAANZ Journal, 3, 44-66. https://doi.org/10.26473/ATLAANZ.2018.1/004

Cameron, C., \& Catt, C. (2014). Learning centre practice in Aotearoa/New Zealand: Preliminary report. In H. Martin \& M. Simkin (Eds.), Hīkina te manuka!: Learning connections in a changing environment: Proceedings of the 2013 Annual International Conference of the Association of Tertiary Learning Advisors of Aotearoa/New Zealand (ATLAANZ) (pp. 1-18). ATLAANZ. 
Council for the Advancement of Standards in Higher Education. (2019). Academic advising programs: CAS contextual statement.

https://www.sbctc.edu/resources/documents/about/task-forces-work-groups/ctccounselors/academic-advising-programs-2019.pdf

Draper, M., \& Barton, D. (n.d.). Introducing UKAT professional recognition [Video]. UKAT Professional Recognition. https://s3-eu-west-1.amazonaws.com/ukatresources/Video/Recognition/Introducing\%20Professional\%20Recognition.mp4

Ferlie, E. Musselin, C., \& Andresani, G. (2008). The steering of higher education systems: A public management perspective. Higher Education, 56(3), 325-348. https://doi.org/10.1007/s10734-008-9125-5

Griffith University. (n.d.). What is a learning adviser? https://studenthelp.secure.griffith.edu.au/app/answers/detail/a_id/1735/ /what-is-alearning-adviser\%3F

Harper, R. (2018). Learning advising: Forces shaping our work, and the opportunities they offer. https://atlaanz.org/wpcontent/uploads/2020/09/Harper_ATLAANZ_Keynote_SLIDES.pdf

McFarlane, K. (2016). Tutoring the tutors: supporting effective personal tutoring. Active Learning in Higher Education, 17(1), 77-88. https://doi.org/10.1177/1469787415616720

McGill, C.M., Ali, M., \& Baton, D. (2020). Skills and competencies for effective academic advising and personal tutoring. Frontiers in Education 5: Article 135. https://doi.org/10.3389/feduc.2020.00135

NACADA: The Global Community for Academic Advising. (2006). NACADA concept of academic advising. https://nacada.ksu.edu/Resources/Pillars/Concept.aspx

NACADA: The Global Community for Academic Advising. (2017). NACADA academic advising core competencies model. https://www.nacada.ksu.edu/Resources/Pillars/CoreCompetencies.aspx

Raby, A. (2020). Student voices in personal tutoring. Frontiers in Education 5: Article 120. https://doi.org/10.3389/feduc.2020.00120 
Sannes, A. (2018, May 29). From the president: Conversation on NACADA as a global community for academic advising. NACADA: The global community for academic advising. https://nacada.ksu.edu/Resources/Academic-Advising-Today/ViewArticles/From-the-President-Conversation-on-NACADA-as-a-Global-Communityfor-Academic-Advising.aspx

Sedgwick, C., \& Grey, S. (2018). The struggle for professional voice in a tertiary education market. New Zealand Sociology,33(2), 133-167.

Sedgwick, C., \& Proctor-Thomson, S.B. (2019). The state of the public tertiary education sector survey, 2018. Tertiary Education Union, Te Hautū Kahurangi o Aotearoa.

Shear, B. W., \& Hyatt, S. B. (2017). Introduction: Higher education, engaged anthropology and hegemonic struggle. In S. B. Hyatt, B. W. Shear \& S. Wright (Eds.), Learning under neoliberalism: Ethnographies of governance in higher education (pp. 1-29). Berghahn Books.

Thurmond, K.C., \& Miller, M.A. (2006). The history of NACADA. NACADA: The Global Community for Academic Advising. https://nacada.ksu.edu/About-Us/History.aspx

United Kingdom Advising and Tutoring. (2019). Professional framework for advising and tutoring. UKAT. https://www.ukat.uk/standards/professional-framework-foradvising-and-tutoring

United Kingdom Advising and Tutoring. (n.d.-a). About UKAT. UKAT. https://www.ukat.uk/community/about-us/

United Kingdom Advising and Tutoring. (n.d.-b). Professional recognition. UKAT. https://www.ukat.uk/standards/professional-recognition/

Weideman, A. (2018). Academic literacy: Five new tests. Geronimo Distribution.

Woods, K. (2020). The development and design of an interactive digital training resource for personal tutors. Frontiers in Education 5: Article 100. https://doi.org/10.3389/feduc. 2020.00100 